\title{
Impact of multivitamin and mineral supplements on mortality and nutritional status of hospitalized severely malnourished HIV/AIDS infected children
}

\author{
Léon G. Blaise Savadogo ${ }^{1,2,3}$, Philippe Donnen ${ }^{3}$, Fla Kouéta ${ }^{4}$, Eléonore Kafando ${ }^{4}$, Philippe Hennart ${ }^{3}$, \\ Michèle Dramaix ${ }^{3}$

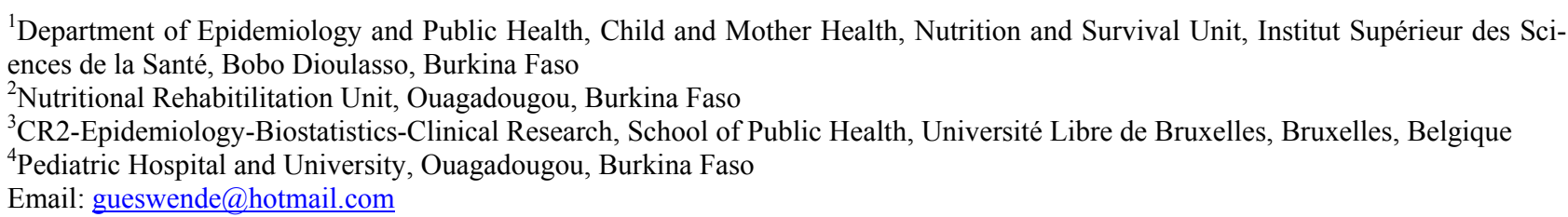

Received 20 September 2013; revised 20 October 2013; accepted 28 October 2013

Copyright (C) 2013 Léon G. Blaise Savadogo et al. This is an open access article distributed under the Creative Commons Attribution License, which permits unrestricted use, distribution, and reproduction in any medium, provided the original work is properly cited.

\begin{abstract}
Micronutrient deficiencies, in HIV/AIDS infected children, are common and associated with disease progression and increased mortality. There is no evidence to support specific recommendation for in-patient treatment of severely malnourished HIV/AID infected children. We analyzed the impact of daily oral multivitamin and mineral supplementation on nutritional status and on mortality rate, of severely malnourished HIV/AIDS infected infants, hospitalized in a feeding therapeutic center. Children were randomized at admission in one of the two treatment groups: WHO standard group or additional dose group. The trial has been approved by the national health research ethics committee. Case fatality rate was high in each group. There was no difference in mortality rate between WHO standard group (mortality rate $=16.9 \%$ ) and "additional dose" group (mortality rate $=17.6 \%$ ). Kaplan Meir survival curves did not differ between the two groups, ( $p$ Log Rank = 0.87). During the inpatient follow-up, the median weight gain $(\mathrm{g} / \mathrm{kg} / \mathrm{d})$ was low in groups and did not differ between WHO standard group $(8.88 \mathrm{~g} / \mathrm{kg} / \mathrm{d}$ Min $=4.70$, Max $=17.23)$ and "additional dose" group $(10.50 \mathrm{~g} / \mathrm{kg} / \mathrm{d}$, Min $=3.29$ Max $=17.81)($ Wilcoxon test $p$-value $=0.10)$. From admission to discharge, anthropometric Z-scores means evolution did not differ between the two groups: WHZ $(p=0.74)$, WAZ $(p=0.79)$ and MUAC $(p=$ $0.73)$. In this randomized trial among severely malnourished HIV/AIDS infected children, we found no evidence that the provision of daily additional micronutrient dose during inpatient treatment, compared
\end{abstract}

to WHO standard, improves nutritional status or reduces case fatality rate. Rigorous malnutrition inpatient treatments, including effective HIV/AIDS management, improve nutritional status of severely malnourished HIV infected children.

Keywords: Multivitamin; Mortality; Nutritional Status; Malnourished; HIV; Children

\section{INTRODUCTION}

During the last year, in many low income countries, interventions to expand human immunodeficiency virus (HIV) prevention, treatment and care for women and children intensified. In 2010, according to UNAIDS statistics, $35 \%$ of pregnant women in low- and middle-income countries received HIV testing and the coverage of pregnant women receiving effective treatment for preventing mother-to-child transmission was estimated $48 \%$ (20\% in Burkina Faso). Despite the efforts made, in low-income countries, many infants continue to be infected each year and often die prematurely. Infant HIV mortality rate, in the absence of treatment, is the greatest during the early years of life $[1,2]$. In low-income countries, HIV/AIDS infected children care interventions coverage remains very low, specifically in rural areas. In west and central Africa, from WHO-UNICEF-UNAIDS statistics, estimated antiretroviral therapy coverage among children was around $13 \%$.

Several observational studies reported large micronutrient deficiencies in HIV/AIDS infected adults and children [3-6]; and indicated that those low blood levels are associated with HIV disease progression and increased 
mortality [7-9]. Some studies reported effectiveness of micronutrient supplementation on morbidity and immune status among HIV-infected none severely malnourished children [10-12].

Severe acute malnutrition (SAM) remains a major problem for HIV-infected children and an important risk factor for mortality. Observational studies reported HIV/ AIDS as severe malnutrition etiologies and a high prevalence of HIV/AIDS among hospitalized severely malnourished children [13-19]. Some studies indicate failure of HIV/AIDS children to respond to malnutrition inpatient treatment with high case fatality rates [20-22].

Improved nutritional treatment may enhance antiretroviral therapy (ART) effectiveness for severely malnourished HIV/AIDS infected children. Due to diagnosis and referral delay, ART is not provided immediately and currently with malnutrition treatment for HIV/AIDS malnourished children hospitalized in nutrition rehabilitation unit in low-income countries.

The benefice of micronutrients in immune function is established [23,24]. Evidence-based response is required to reduce impact that HIV/AIDS and malnutrition have on each other. Some evidence suggested that for HIV/ AIDS infected children, with weight loss, energy intake needs to be increased. But evidence to support specific recommendation for in-patient treatment of severely malnourished HIV/AID infected children is not yet available, then up to now World Health Organization (WHO) rehabilitation protocol is followed for HIV/AIDS infected or uninfected children. All severely malnourished children have vitamin and mineral deficiencies. One of the treatment steps is to correct those micronutrient deficiencies. Evidence effect of additional dose of micronutrients on severely malnourished HIV/AIDS infected mortality rate decrease and on nutrition status is not available. Does current protocol need to be modified for HIV/AIDS infected children? No consistent response is available.

Given the failure and the high case fatality rates of HIV/AIDS infected malnourished children to respond to inpatient treatment, we tested the impact of oral multivitamin and mineral additional dose to severely malnourished HIV/AIDS infected infants, hospitalized in a nutriational rehabilitation unit.

This paper describes the results of a randomized clinical trial whose aims were to analyze the impact of daily oral multivitamin and mineral supplementation on nutriational status and on intra-hospital mortality rate, of severely malnourished HIV/AIDS infected infants, hospitalized in a nutritional rehabilitation unit.

\section{MATERIAL AND METHODS}

\subsection{Study Design and Site}

The study was a randomized controlled trial conducted between 2006 and 2008 at a nutritional rehabilitation center for inpatient treatment of severely malnourished children, in Ouagadougou.

At this center, malnourished children are hospitalized with their mother. A trained care provider's staff, leaded by a medical doctor, was in charge of the management. Appropriate case management and follow-up care, based on WHO guidelines was performed. The center was related to the pediatric hospital of Ouagadougou where children with complications are referred by car.

\subsection{Study Population}

Severe acute malnutrition (SAM) diagnostic is based on severe wasting, as a weight-for-height below $-3 \mathrm{SD}$ or below $70 \%$ of median (based on NCHS reference) or the presence of nutritional oedema affecting both feet.

After admission, severely malnourished children parents (mothers and father) consent was required for HIV diagnosis. When parents provided informed consent for HIV testing, the child blood sample were collected and identified by a single code and immediately transferred to Ouagadougou pediatric hospital laboratory for analyses. To reduce testing cost, for all consent children, a first level antibody tests was used and polymerase chain reaction (PCR) test was used when antibody test was positive. The testing result was available within 24 hours. When their parents provided informed consent, HIV/ AIDS infected malnourished children were consecutively enrolled in the study and assigned to the intervention or "standard care" (WHO standard) treatment group. All patients were ART naïve at the admission.

Computer generated randomization list have been prepared before the beginning of the study. Due to the sample size and number of treatment group (two groups), permuted blocs of size 4 have been used. Consecutive HIV/AIDS infected children with parental informed consent are enrolled by bloc of 4 participants. For a bloc, random treatment allocation has been performed for each subject. Treatment groups was identify by A (additional dose group) and B (WHO standard group). For the two treatment groups, six alternatives of 4 blocs were possible: AABB, ABAB, ABBA, BAAB, BABA, and BBAA. Each alternative bloc was assigned number from 1 to 6 . For preparing the randomization list, a $\mathrm{K}$ random number was generated by computer and list was established based on 1 for $\mathrm{AABB}, 2$ for $\mathrm{ABAB}, 3$ for $\mathrm{ABBA}, 4$ for $\mathrm{BAAB}, 5$ for BABA, 6 for BBAA.

\subsection{Study Intervention and Regimen}

The trial multivitamins were manufactured by NUTRISET, France. And locally, the daily regimen was provided to care providers in sterile dosed plastic.

The micronutrients administered doses were defined based on WHO guidelines for inpatients treatment of severely malnourished children and on the specific daily 
additional needs for HIV/AIDS infected children.

The study regiment contains multivitamins for daily $100 \mathrm{ml}$ feeding formula:

WHO standard group: Multivitamins: vitamin A (300 mcg), vitamin D (3 mcg), vitamin E (2.2 mg), vitamin C (10 mg), vitamin B1 $(0.07 \mathrm{mg})$, vitamin B2 $(0.2$ $\mathrm{mg})$, vitamin B6 $(0.07 \mathrm{mg})$, vitamin B12 $(0.1 \mathrm{mcg})$, vitamin $\mathrm{K}(4 \mathrm{mcg})$, biotin $(0.01 \mathrm{mg})$, follic acid $(35 \mathrm{mcg})$, pantothenic acid $(0.3 \mathrm{mg})$ and niacin $(1 \mathrm{mg})$. And Minerals: Potassium $(117 \mathrm{mg})$, magnesium $(7.3 \mathrm{mg})$, zinc (2 $\mathrm{mg})$, copper $(0.28 \mathrm{mg})$, iron $(0 \mathrm{mg})$, iodine $(7.7 \mathrm{mcg})$, selenium (4.7 mcg).

Treatment group(additional dose group): Multivitamins: vitamin A (450 mcg), vitamin D $(4.5 \mathrm{mcg})$, vitamin E $(3.3 \mathrm{mg})$, vitamin $\mathrm{C}(15 \mathrm{mg})$, vitamin $\mathrm{B} 1(0.11$ $\mathrm{mg})$, vitamin B2 $(0.3 \mathrm{mg})$, vitamin B6 $(0.11 \mathrm{mg})$, vitamin B12 $(0.15 \mathrm{mcg})$, vitamin $\mathrm{K}(6 \mathrm{mcg})$, biotin $(0.02 \mathrm{mg})$, follic acid $(52.5 \mathrm{mcg})$, pantothenic acid $(0.45 \mathrm{mg})$ and niacin $(1.5 \mathrm{mg})$. And Minerals: Potassium $(175.5 \mathrm{mg}$ ), magnesium (10.95 mg), zinc (3 mg), copper $(0.42 \mathrm{mg})$, iron $(0 \mathrm{mg})$, iodine $(11.55 \mathrm{mcg})$, selenium $(7.05 \mathrm{mcg})$.

The trial has been approved by the national health research ethics committee.

\subsection{Standard of Care}

Patients received standard inpatient treatment for severely malnourished children with initial stabilization phase and rehabilitation phase, except for micronutrients (concerned by the trial). Treatment procedures were similar for marasmus and kwashiorkor. For feeding, daily and hourly volume was adapted to the child weight and presence of oedema.

HIV/AIDS infected children was referred to pediatric hospital to be integrated to HIV/AIDS follow-up cohort and eligible's patients received antiretroviral treatment after. Due to delay between HIV screening, stabilization and procedures at pediatric hospital, ART started several weeks after admission in the feeding therapeutic center.

All nutritional treatment, antiretroviral treatment and opportunistic infections management were offered, using national guidelines. Testing including PCR and transport to pediatric hospital were offered.

\subsection{Study Samples Size}

The study enrolled 550 malnourished children, 482 have been tested for HIV and 65 was founded HIV/AIDS infected. We obtained free participation of all infected children from parents. The trial enrolled 65 malnourished HIV/AIDS infected children, 34 in the "WHO standard group" and 31 in the "additional dose group".

\subsection{Data Collection}

At the enrollment, daily and at discharge, trained re- search nurses collected data on children's socio-demographic (sex, age, parent residence), feeding, anthropometry and clinical signs. The child age was determined using date of birth recorded from its mother pregnancy card and date of enrollment. Weight was measured in $\mathrm{kg}$ using recommended scale with a precision of $0.1 \mathrm{~kg}(100$ g). Length of less than 02 years old child was measured in centimeters using length board (horizontal infantometer) with a precision $0.1 \mathrm{~cm}(1 \mathrm{~mm})$ and height of 2 years or older child able to stand was measured in $\mathrm{cm}$ using height board (vertical stadiometer) with a precision 0.1 $\mathrm{cm}(1 \mathrm{~mm})$. If the child was not able to stand for any reason, length was measured using length board and subtract $0.7 \mathrm{~cm}$ to convert in to height.

Oedema of both feet was automatically considered as severely malnourished case.

Mid-upper arm circumference (MUAC) $(\mathrm{cm})$ was recorded for completed 3 months children.

After discharge, a monthly visit was organized for children.

\subsection{Laboratory Analyses}

Anti body test, PCR for HIV diagnosis, CD4+ cell count, blood cell count and hemoglobin was performed for all children at Ouagadougou pediatric hospital laboratory.

\subsection{Study Outcomes}

The trial aimed to analyze the impact of daily additional oral multivitamin and mineral dose on nutritional status and on intra-hospital mortality, of severely malnourished HIV/AIDS infected infants.

Using NCHS growth standards, child age, sex, weight and length or height measurements were been used to calculate following indicators: Weight-for-length and weight-for-height $\mathrm{z}$-score (WHZ), weight-for-age z-core (WAZ) and length or height-for-age z-score (HAZ) at admission and discharge.

The study outcomes were: mortality rate and the difference in attained WHZ, WAZ and MUAC, and proportions of recovered at discharge and weight gain.

\subsection{Statistical Analyses}

We used "intent to treat" to analyze treatment impact. Usual statistics methods were applied. We used Pearson's Chi square test or Fisher's exact test to compare proportions; ANOVA test, Student's t-test or MannWhitney and Wilcoxon test to compare means or medians. Significant level was 0.05 . General linear model has been used to analyze repeated measurements. Mortality relative risks with confidence interval (CI95\%) have been calculated to estimate the impact of the treatment. Cox proportional hazard model has been used to investigate the treatment effect. 
The following lower and upper standard deviation (SD) boundaries have been used: WHZ $(-4,+6)$, HAZ $(-6,+6)$ and WAZ $(-6,+6)$. Weight gain was calculated as $\mathrm{g} / \mathrm{kg} / \mathrm{day}$. 20.

The data were analyzed using SPSS software version

\section{RESULTS}

From 550 admitted severe malnourished, 482 have been tested and 65 were HIV/AIDS infected and consented to participate in the trial. The distribution of children by group is presented in "Figure 1".

Children characteristics, including demographic, anthropometrics and clinical data, viral load and immune status did not differ between the two treatment groups "Table 1".

The median hospitalization time did not differ between WHO standard group (25.5 days) and the "additional dose" group (28.0 days), $\mathrm{p}=0.79$.

Case fatality rate was high is each group. There was no difference in mortality rate between WHO standard group (mortality rate $=16.9 \%$ ) and "additional dose" group (mortality rate $=17.6 \%$ ). Mortality relative risk was $1.09,95 \%$ IC [ 0.37 - 3.23] for WHO standard group, $\mathrm{p}=0.87$. Kaplan Meir survival curves do not differ between the two groups, ( $p$ Log Rank = 0.87) "Figure 2".

From Cox regression there was no effect of additional dose on inpatient mortality rate, (WHO standard group $\mathrm{HR}=1.7$, CI: 0.44-7,1, Wald Chi square p-value $=0.4$ ).

During the inpatient follow-up, the median weight gain $(\mathrm{g} / \mathrm{kg} / \mathrm{d})$ was low in groups and did not differ between WHO standard group $(8.88 \mathrm{~g} / \mathrm{kg} / \mathrm{d}$ Min $=4.70$, Max $=17.23)$ and "additional dose" group $(10.50 \mathrm{~g} / \mathrm{kg} / \mathrm{d}$, Min $=3.29$ Max $=17.81)($ Wilcoxon test p-value $=0.10)$. But within each groups subjects, median weight gain progressed significantly between day14 and day22: WHO standard group (day14: $5.2 \mathrm{~g} / \mathrm{kg} / \mathrm{d}$, Min $=2.5$ Max $=13,3 ;$ day22: $8.2 \mathrm{~g} / \mathrm{kg} / \mathrm{d}, \operatorname{Min}=4.7 \mathrm{Max}=20.2)($ Wilcoxon test $\mathrm{p}$-value $=0.000$ ); Additional dose group (day14: $5.9 \mathrm{~g} / \mathrm{kg} / \mathrm{d}, \mathrm{Min}=1.0 \mathrm{Max}=11.6$; day22: 7.7 $\mathrm{g} / \mathrm{kg} / \mathrm{d}, \operatorname{Min}=2.1$ Max $=16.2)($ Wilcoxon test $\mathrm{p}$-value $=$ 0.005 ).

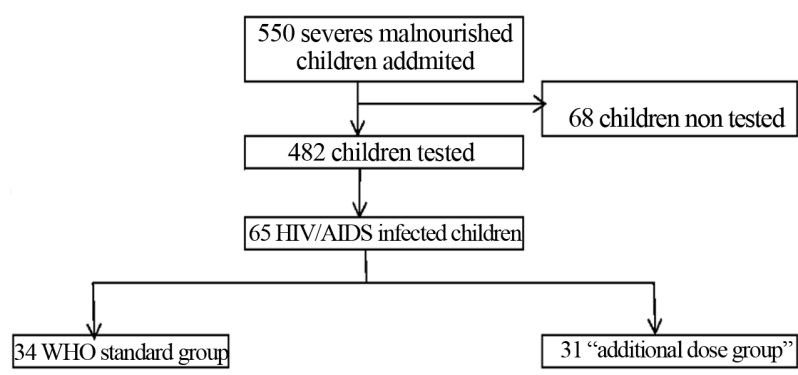

Figure 1. Study profile.
Table 1. Demographic characteristics, nutritional status, clinical data, viral load and immune status of the two study groups on admission.

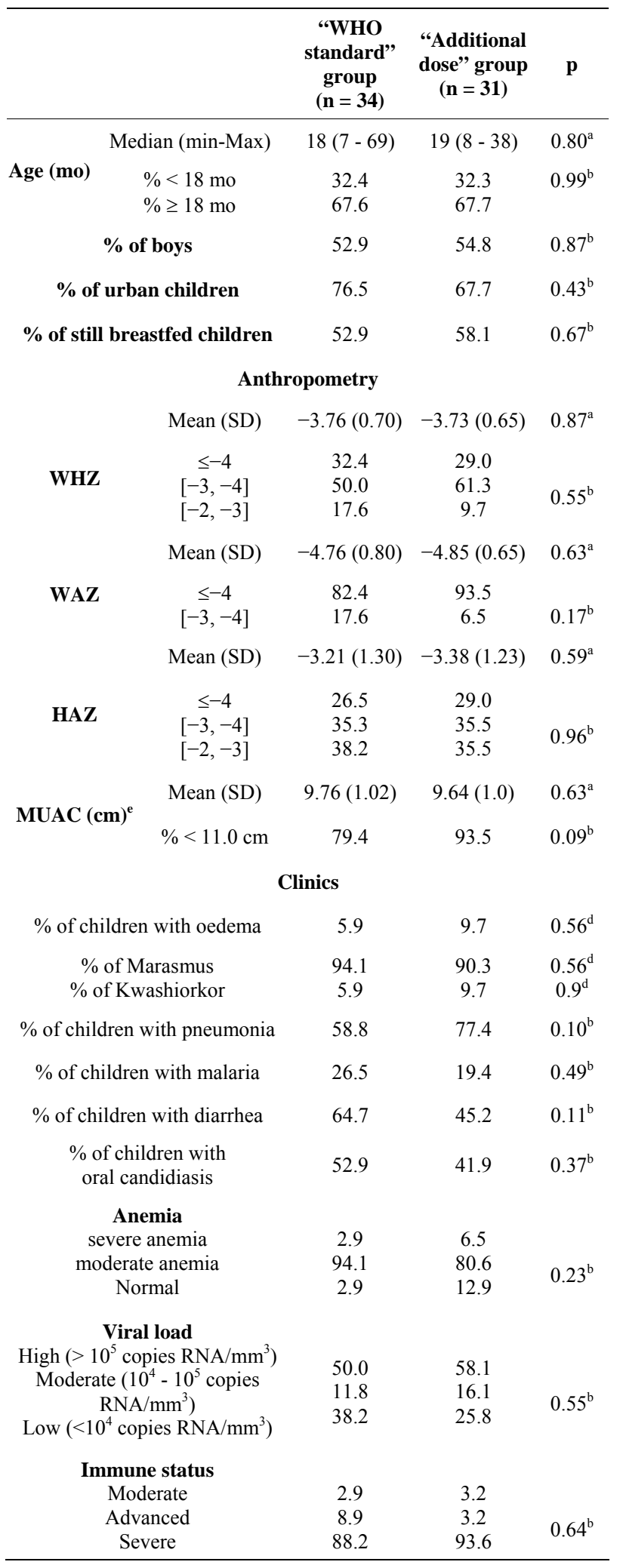

${ }^{\mathrm{a}}$ Mann-Whitney's non-parametric test; ${ }^{\mathrm{b}}$ Pearson's $\chi^{2}$ test; ${ }^{\mathrm{C}}$ Independent t-test; ${ }^{\mathrm{d}}$ Yate's $\chi^{2}$ test; ${ }^{\mathrm{e}}$ Children aged $>6$ months. 


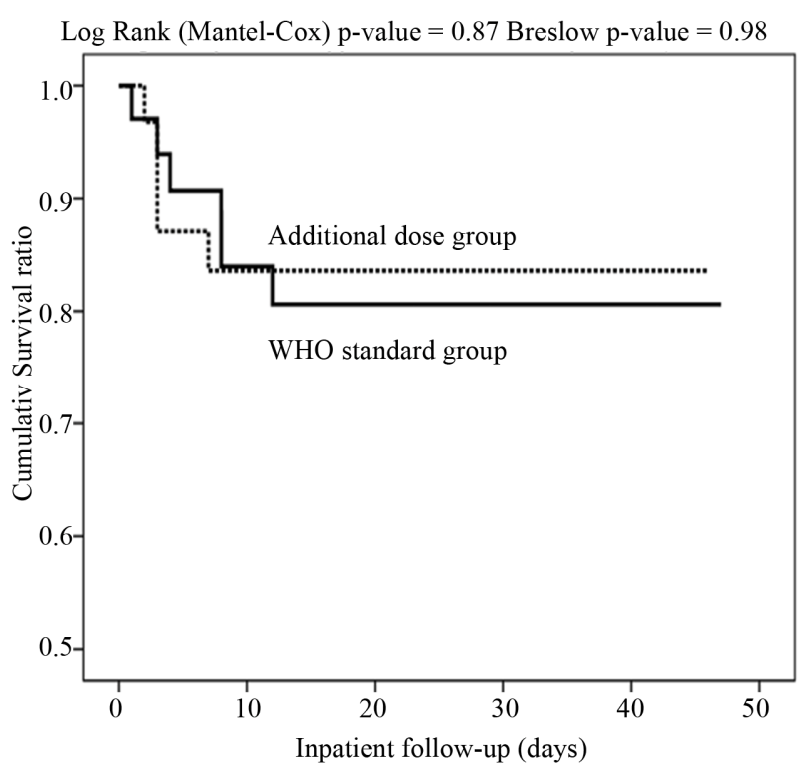

Figure 2. Kaplan-Meier survival curves.

At discharge, proportion of recovered children did not differ between groups (Log Rank p-value $=0.99)$.

From admission to discharge, anthropometric Z-scores means evolution did not differ between the two groups: WHZ (between group: $p=0.74$ ), WAZ (between group: $p=0.79$ ) and MUAC (between group: $p=0.73$ ) "Figures 3(a)-(c)". But within group's subjects anthropometric Z-scores means evolution was significant: WHZ (within group's subjects: $p=0.000$ ), WAZ (within group's subjects: $p=0.000$ ) and MUAC (within group's subjects: $\mathrm{p}=0.000)$.

\section{DISCUSSION}

Adequate nutrition is important, at any stage of life, for metabolic system, growth function and optimal immune. There is inextricable link between nutritional status and disease.

SAM's case fatality rate remained high in low incomes countries. Many malnourished children are HIV/ AIDS infected. Substantial reductions in mortality rates have been achieved with WHO guidelines for the inpatient treatment of severely malnourished children. To improve disease-related mortality, clinical outcomes and nutritional recovery of severely malnourished HIV-infected children integrating HIV and nutritional management is critical.

In this randomized clinical trial among severely malnourished HIV/IADS infected children, ART naïve at admission, hospitalized for inpatient treatment for their malnutrition, daily additional micronutrient dose supplementation, compared to WHO standard, did not improve means anthropometric Z-scores, weight gain or reduce case fatality rate. Despite to limited sample size in the

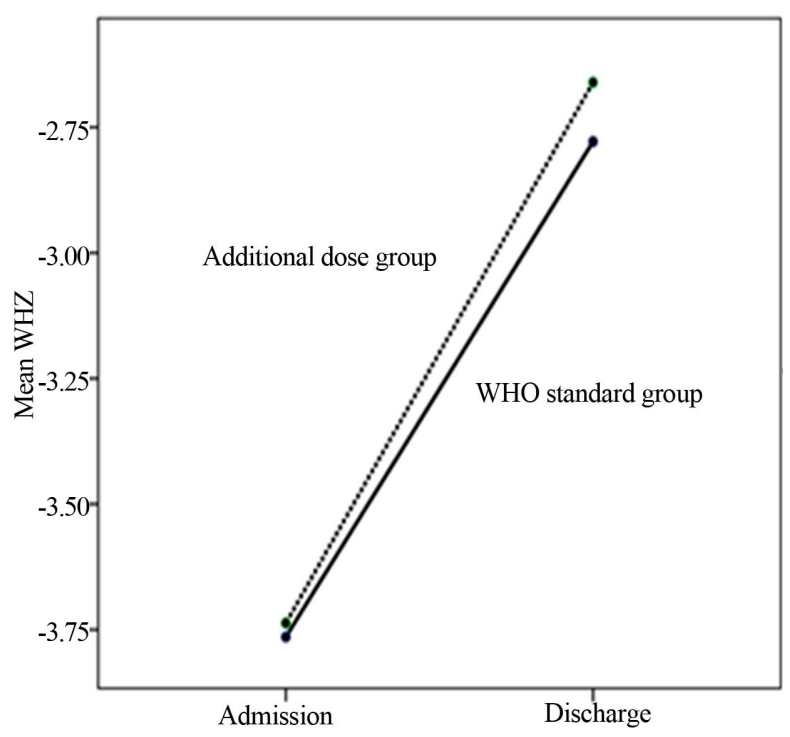

(a)

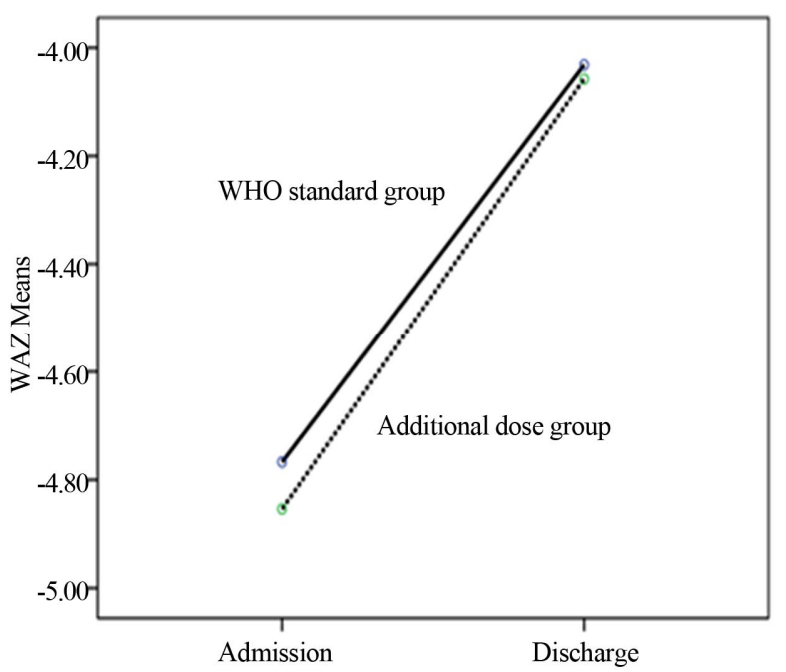

(b)

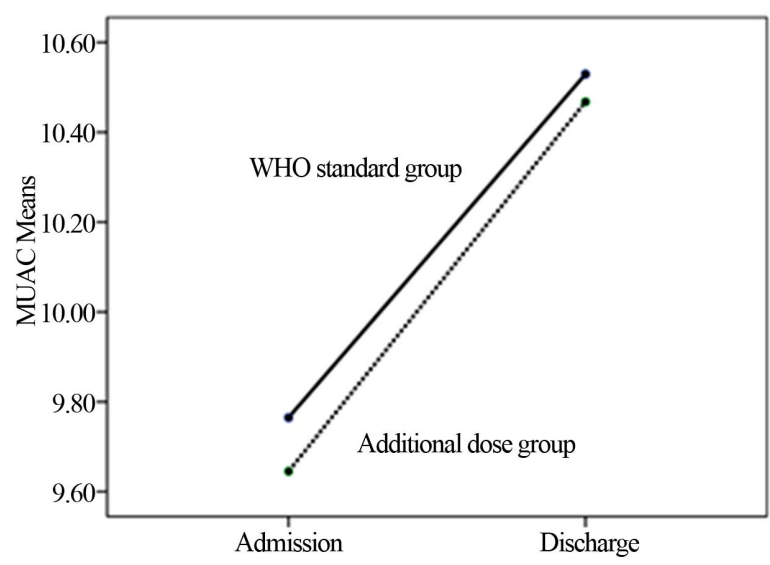

(c)

Figure 3. (a)-(c) From admission to discharge anthropometric Z-scores means evolution within each group subjects and between groups. 
treatments groups, the strong follow-up and randomized design of the study, face to the lake of evidence, allow for consistency of the observed effect.

For SAM management, in general, high mortality rate and poor rate of weight gain result from a failure of treatment practices.

Some authors [24] reported that vitamin A supplementation decreases mortality rate in HIV-infected children and should be considered in the care for these children in developing countries. A study in Burkina Faso reported benefit effect of spirulina platensis supplement without ART on malnutrition recovery of HIV infected malnourished children [25].

But despite to rigorous follow-up and treatment, in our study, in the two treatment groups, case fatality rate remained high and occurred in the first hospitalization week. Severe acute malnutrition (SAM) in HIV-infected children is associated with metabolic complications, micronutrient deficiencies, and severe infections, which contribute to the high mortality. Management is critical at the firth week.

Paton et al. reported that malnutrition, at the time of starting ART, was associated significantly with decreased survival [26].

During the hospital follow-up, within each group's subjects, median weight gain progressed significantly between day 14 and day 22 and within group's subjects anthropometric Z-scores means evolution was significantly positive from admission to discharge. Nutritional management combined to effective antiviral treatment produce improvement in health, including nutritional status of severely malnourished children ART naïve at the beginning of nutrition inpatient treatment.

We did not found consistent scientific review about effects of micronutrient supplementation on severely malnourished children mortality rate and on nutritional status. Cochrane database 2013 review reported no evidence based about the effects of macronutrient supplementation on morbidity and mortality in people living with HIV [27].

In conclusion, in this randomized trial among severely malnourished HIV/AIDS infected children, we found no evidence that the provision of daily additional micronutrient dose during inpatient treatment, compared to WHO standard, improves nutritional status or reduces case fatality rate. But rigorous malnutrition inpatient treatments, including effective HIV/AIDS management, improve nutritional status of severely malnourished HIV infected children.

\section{ACKNOWLEDGEMENTS}

Commission universitaire pour le développement (CUD), Belgium, founded multivitamins, laboratory analysis, medicines for opportunistic diseases.

\section{REFERENCES}

[1] Brahmbhatt, H., Kigozi, G., Wabwire-Mangen, F., Serwadda, D., Lutalo, T., Nalugoda, F., Sewankambo, N., Kiduggavu, M., Wawer, M. and Gray, R. (2006) Mortality in HIV-infected and uninfected children of HIV-infected and uninfected mothers in rural Uganda. Journal of Acquired Immune Deficiency Syndromes, 41, 504-508. http://dx.doi.org/10.1097/01.qai.0000188122.15493.0a

[2] Kawo, G., Karlsson, K., Lyamuya, E., Kalokola, F., Fataki, M., Kazimoto, T., Kitundu, J., Msaky, H., Munubhi, E., Ostborn, A., Bredberg-Raden, U., Swai, A., Mbise, R., Msengi, A., Mhalu, F. and Biberfeld, G. (2000) Prevalence of HIV type 1 infection associated clinical features and mortality among hospitalized children in Dar es Salam, Tanzania. Scandinavian Journal of Infectious Diseases, 32, 357-363.

http://dx.doi.org/10.1080/003655400750044917

[3] Kafwembe, E.M., Kelly, P. and Ngalande, P. (2001) Vitamin A levels in HIV/AIDS. East African Medical Journal, 78, 451-453. http://dx.doi.org/10.4314/eamj.v78i9.8972

[4] Van-Staden, A.M., Barnard, H.C., Nel, M., Attwood, E.M., Oosthuizen, G.M., Dannhauser, A., Van-der-Ryst, E. and LeRoux, G.D. (1998) Nutritional status of HIV-1 seropositive patients in the Free State Province of South Africa-laboratory parameters. Central African Journal of Medicine, 44, 246-250.

[5] Beach, R.S., Mantero Atienza, E., Shor-Posner, G., Javier, J.J., Szapocznik, J. and Morgan, R. (1992) Specific micronutriment abnormalities in asymptomatic HIV-1 infection. AIDS, 6, 701-708.

http://dx.doi.org/10.1097/00002030-199207000-00013

[6] Bogden, J.D., Baker, H. and Frank, O. (1990) Micronutriment status and human immunodeficiency virus infection. Annals of the New York Academy of Sciences, 587, 189. 195.

[7] Baum, M.K., Shor-Posner, G. and Lu, Y. (1995) Micronutrients and HIV-1 disease progression. AIDS, 9, 10511056.

http://dx.doi.org/10.1097/00002030-199509000-00010

[8] Tang, A.M., Graham, N.M.H. and Saah, A.J. (1996) Effects of micronutrient intake on survival in human immunodeficiency virus type 1 infection. American Journal of Epidemiology, 143, 1244-1256.

http://dx.doi.org/10.1093/oxfordjournals.aje.a008712

[9] Fawzi, W. (2003) Micronutrients and human immunodeficiency virus type 1 disease progression among adults and children. Clinical Infectious Diseases, 37, S112-S116. http://dx.doi.org/10.1086/375882

[10] Young, T. (2006) Effects of micronutrient supplementation on morbidity and mortality among HIV-infected individuals-A summary of the evidence. South African Medical Journal, 96, 1062-1064.

[11] Bobat, R., Coovadia, H., Stephen, C., Naidoo, K.L., McKerrow, N., Black, R.E. and Moss, W.J. (2005) Safety and efficacy of zinc supplementation for children with HIV-1 
infection in South Africa: A randomised double-blind placebo-controlled trial. Lancet, 366, 1862-1867. http://dx.doi.org/10.1016/S0140-6736(05)67756-2

[12] Coutsoudiis, A., Bobat, R.A., Coovadia, H.M., Kuhn, L., Tsai, W-Y. and Stein, Z.A. (1995) The effects of vitamin a supplementation on the morbidity of children born to HIV-infected women. American Journal of Public Health, 85, 1076-1081. http://dx.doi.org/10.2105/AJPH.85.8 Pt 1.1076

[13] Sombié, I., Nacro, B., Tiendrébéogo, S., Dao, B., Cartoux, M., Meda, N., Ky-Zerbo, O., Dabis, F., Mandelbrot, L. and Van de Perre, P. (1999) Maternal HIV infection and the anthropometric characteristics of children at birth in Burkina Faso. Sante, 9, 173-177.

[14] Lepage, P., Msellati, P., Hitimana, D.G., Bazubagira, A., Van Goethem, C., Simonon, A., Karita, E., Dequae-Merchadou, L., Van de Perre, P. and Dabis, F. (1996) Growth of human immunodeficiency type 1-infected and uninfected children: A prospective cohort study in Kigali, Rwanda, 1988 to 1993. The Pediatric Infectious Disease Journal, 15, 479-485. http://dx.doi.org/10.1097/00006454-199606000-00003

[15] Prazuck, T., Tall, F. and Nacro, B. (1993) HIV infection and severe malnutrition: A clinical and epidemiological study in Burkina Faso. AIDS, 7, 103-108. http://dx.doi.org/10.1097/00002030-199301000-00016

[16] Somé, J.F., Bellamy, G. and Auregan, G. (2000) Malnutrition et statut sérologique des enfants admis dans un CREN de Ouagadougou: Comparaison des aspects anthropométriques, biologiques et évolutifs. 9èmes journées des sciences de la santé, 9-12, Bobo-Dioulasso.

[17] Ticklay, I.M., Nathoo, K.J., Siziya, S. and Brady, J.P. (1997) HIV infection in malnourished children in Harare, Zimbabwe. East African Medical Journal, 74, 217-220.

[18] Mgone, C.S., Mhalu, F.S. and Shao, J.F. (1991) Prevalence of HIV1 infection and symptomatology of AIDS in severely malnourished children in Dars Es Salaam, Tanzania. Journal of Acquired Immune Deficiency Syndromes, 4, 910-913.

[19] Collins, S., Dent, N., Binns, P., Bahwere, P., Sadler, K. and Hallam, A. (2006) Management of severe acute malnutrition in children. Lancet, 368, 1992-2000. http://dx.doi.org/10.1016/S0140-6736(06)69443-9
[20] Beau, J.P., Imboua-Coulibaly, L. and Du Lou, A.D. (1999) The effect of nutritional management on the mortality of malnourished uninfected and infected with the human immunodeficiency virus. Sante, 9, 163-167.

[21] Puoane, T., Sanders, D., Chopra, M., Ashworth, A., Strasser, S., McCoy, D., Zulu, B., Matinise, N. and Mdingazwe, N. (2001) Evaluating the clinical management of severely malnourished children - A study of two rural district hospitals. South African Medical Journal, 91, 137-141.

[22] Kessler, L., Daley, H., Malenga, G. and Graham, S. (2000) The impact of the human immuno deficience virus 1 on the management of severe malnutrition in Malawi. Annals of Tropical Paediatrics, 20, 50-56. http://dx.doi.org/10.1080/02724930092075

[23] Buys, H., Hendricks, M., Eley, B. and Hussey, G. (2002) The role of nutrition and micronutrients in paediatric HIV infection. SADJ, 57, 454-456.

[24] Semba, R.D., Ndugwa, C., Perry, R.T., Clark, T.D., Jackson, J.B., Melikian, G., Tielsch, J. and Mmiro, F. (2005) Effect of periodic vitamin A supplementation on mortality and morbidity of human immunodeficiency virus-infected children in Uganda: A controlled clinical trial. $\mathrm{Nu}$ trition, 21, 25-31. http://dx.doi.org/10.1016/j.nut.2004.10.004

[25] Simpore, J., Zongo, F., Kabore, F., Dansou, D., Bere, A., Nikiema, J-B., Pignatelli, S., Biondi, D.M., Ruberto, G. and Musumeci, S. (2005) Nutrition Rehabilitation of HIVInfected and HIV-Negative Undernourished Children Utilizing Spirulina. Annals of Nutrition and Metabolism, 49, 373-380. http://dx.doi.org/10.1159/000088889

[26] Paton, N.I., Sangeetha, S., Earnest, A. and Bellamy, R. (2006) The impact of malnutrition on survival and the CD4 count response in HIV-infected patients starting antiretroviral therapy. HIV Medicine, 7, 323-330. http://dx.doi.org/10.1111/j.1468-1293.2006.00383.x

[27] Grobler, L., Siegfried, N., Visser, M.E., Mahlungulu, S.S. and Volmink, J. (2013) Nutritional interventions for reducing morbidity and mortality in people with HIV. Cochrane Database of Systematic Reviews, 2, CD004536. http://onlinelibrary.wiley.com/doi/10.1002/14651858.CD 004536.pub3/pdf 